\title{
Multi-attribute Decision Model of Green Supplier Selection under the Low-carbon Economy
}

\author{
Congjun Rao, Ningjuan Zhang \\ College of Mathematics and Physics, Huanggang Normal University, \\ Huanggang 438000, China \\ cjrao@163.com
}

Keywords: Green supplier; Green supplier selection; Low-carbon economy; AHP

\begin{abstract}
On the background of global warming, energy shortages and environmental pollution, people pay more attention to the low-carbon economy. In this paper, the problem of green supplier selection based on low-carbon economy is studied. Concretely, an evaluation index system for green supplier selection under the low-carbon economy is presented, and then a multi-attribute decision model of green supplier selection is established based on the method of analytic hierarchy process (AHP). This model provides decision reference for the department of supply chain management.
\end{abstract}

\section{Introduction}

Due to the increasingly serious global environmental problems, there are serious threat for the human survival and development. In today's global climate growing, countries are seeking the path of sustainable development. China is the largest developing country in the world at present, but also is the superpower on greenhouse gas emissions. Thus, to study the problem of carbon dioxide emissions is not only conducive to China's sustainable development, but also makes an important contribution to the global greenhouse gas emissions and mitigate global warming,. The emergence of green suppliers plays a key role to reduce greenhouse gas emissions, so to seek the right green supplier under low-carbon economy have profound significance to the business development of a company and global climate change.

China has joined the WTO, which provides more and better development platform, but some domestic small and medium sized companies do not change the previous production management idea, and still remain in the previous model of development, so that there are a series of questions in the procurement management of enterprises. First, companies are not good at using the Internet information platform to seek this development opportunities, but stick to the old path of development, i.e., the choice of suppliers to comply with the principle of proximity or from the perspective of a single price consideration, without considering the influence of green suppliers on the low-carbon economy, and can not choose the right green suppliers to cooperate. Secondly, the choice of suppliers is more dependent on the decision of the competent subjective consciousness, so supplier selection contains too much personal subjective factors. Finally, many companies will focus too much on product manufacturers, thus ignoring the concerns of the procurement management. In this case, the purchasing department can easily consider only the price of the product, thereby ignoring other issues, thereby affecting the quality and effectiveness of procurement. So it is of great practical significance to seek effective green supplier selection methods.

For the problem of green supplier selection under low-carbon economy, many experts and scholars established many valuable mathematical models, which provide good guide for us. For example, Sun [1] presented an evaluation index system of sustainable development, and used the methods which combined the qualitative with quantitative idea to evaluate the supplier selection based on the Delphi method and the fuzzy comprehensive evaluation method. He also studied the problem of green supplier evaluation. Song [2] used the AHP method to determine the weights of evaluation attributes, and established a comprehensive evaluation model based on combination weights and triangle fuzzy 
function, and used empirical analysis to verify the validity of the evaluation model. Ruan [3] established a supplier evaluation system in green supply chain management according to the supplier specific circumstances in China's manufacturing enterprises, and then he used the SPSS statistical software to do the clustering analysis for the green supply chain data, and verified the rationality of index classification. At last, he used the method of ELECTRE-I for supplier selection decisions and got the comprehensive evaluation results for manufacturing suppliers.

In this paper, based on the study on the existing supplier selection, we put forward a new evaluation system of green supplier selection under low-carbon economy, and established a multi-attribute decision model for supplier selection based on the theoretical basis of a low-carbon economy and multi-attribute decision making theory. Our aim is to help companies to choose the best suppliers scientifically and effectively.

\section{Evaluation System of Green Supplier Selection}

When we construct the index system of green supplier selection, we should add the low-carbon, environmental and other factors into the traditional supplier selection evaluation system from the theoretical basis and content of green supply chain, which can reflect the social responsibility of corporate, and is line with the development requirements of low-carbon economy and green supply chain. Combined with relevant information of existing supplier selection methods [4-10], here we present an index system which includes five attributes, i.e., environmental performance, economic capacity, production capacity, service capacity and supply capacity, and the sub-attributes of each attribute are listed as shown in Table 1.

Table 1. The evaluation System of Green Supplier Selection

\begin{tabular}{|c|c|}
\hline The upper attribute & The lower attribute \\
\hline$B_{1}$ Production capacity & $\begin{array}{l}C_{1} \text { Quality } \\
C_{2} \text { Technological level } \\
C_{3} \text { Maximum Capacity }\end{array}$ \\
\hline$B_{2}$ Economic capacity & $\begin{array}{l}C_{4} \text { Cost } \\
C_{5} \text { Price } \\
C_{6} \text { Status of funds }\end{array}$ \\
\hline$B_{3}$ Supply capacity & $\begin{array}{l}C_{7} \text { Accuracy rate of supply } \\
C_{8} \text { Supply consumption } \\
C_{9} \text { Timely delivery rate }\end{array}$ \\
\hline$B_{4}$ Service capacity & $\begin{array}{l}C_{10} \text { Service delivery system } \\
C_{11} \text { After-sales Service }\end{array}$ \\
\hline$B_{5}$ Environmental performance & $\begin{array}{l}C_{12} \text { Environmental management } \\
C_{13} \text { Environmental quality certification } \\
C_{14} \text { Green degree of upstream suppliers }\end{array}$ \\
\hline
\end{tabular}

\section{Green Supplier Selection Model Based on AHP}

Based on the evaluation system of green supplier selection listed in Table 1, we present a green supplier selection model based on the method of AHP. The main idea is to do a few steps such as construct hierarchical structure model, construct the two-two comparison matrix, determine the single sorting and hierarchical total sorts, and then get the hierarchy of the components relative to the overall goal of a combination weights, and the final evaluation results of different feasible schemes can be obtained. The detailed steps are given as follows.

Step 1: Determine the weights of decision attributes. 
For the above 14 decision attributes, we can construct the two-two comparison matrix as $A=\left(a_{i j}\right)_{n \times n}$, where $a_{i j}$ denotes the degree of importance between the $i$-th attribute and the $j$-th attribute, and the judgment matrix is mainly constructed by the consistency complementary judgment matrix and the consistency reciprocal judgment matrices. On the structure of the judgment matrix, no matter use which kinds of method, for the establishment of the scale, Thomas L.S aaty suggested to use 1-9 scaling method (see the Table 2), where the values must be positive.

Table 2. 1-9 scaling

\begin{tabular}{cc}
\hline Relative important degree & Meaning \\
\hline 1 & equally important \\
3 & Slightly more important \\
5 & Relative importanc \\
7 & Obviously important \\
9 & Absolute importance \\
$2,4,6,8$ & Adjacent center value judgment \\
reciprocal & A compares $C$ is 5 , then $C$ compares $A$ is $1 / 5$ \\
\hline
\end{tabular}

For the positive reciprocal judgment matrix, the degree of importance between the $i$-th attribute and the $j$-th attribute is $a_{i j}(i, j \in N)$ given by decision maker satisfy the following conditions.

(1) $a_{i j}=\frac{1}{a_{j i}}$;

(2) $a_{i i}=1$.

Step 2: consistency check for matrix $A$

When the judgment matrix is obtained, we must do the consistency check for matrix $A$. If matrix $A$ passes the consistency check, then the weights are significative.

If matrix $A$ don't pass the consistency check, then we must reestimate matrix $A$, until the new matrix passes the consistency check, the weight is effective. In fact, there are two kinds of consistency check methods.

(1) Consistency check of reciprocal judgment matrices

For the reciprocal matrix $A=\left(a_{i j}\right)_{n \times n}$, when the following condition is satisfied

$$
a_{i j}=\frac{a_{i k}}{a_{k j}}(\forall i, j, k=1,2, \ldots, n),
$$

then we call A is a consistency matrix. Due to the maximum eigenvalue of positive reciprocal matrix $\lambda_{\text {max }} \geq n$, but the maximum eigenvalue of consistency matrix satisfies $\lambda_{\max }=n$, and the other eigenvalues are all 0 , thus we judge the consistency of the judgement matrices. The consistency index are defined as $C I=\frac{\lambda_{\max }-n}{n-1}$.

The value of $C I$ is greater, the consistency of matrix is poor. In addition, we introduce another random consistency test index $R I$ to express the mean consistency of random matrix. Thus the consistency ratio is $C R=\frac{C I}{R I}$, then we can use this value to get the consistency judgment result. If $C R \leq 0.1$, then the judgment matrix passes the consistency test. Otherwise, we must modify the judgment matrix until it passes the consistency test.

(2) Consistency test of fuzzy complementary judgment matrix

For the consistency test of fuzzy complementary judgment matrix, we can use a compatibility index to judge. We can use a useful weight solution formula to solve this problem, i.e., 


$$
w_{i}=\frac{\sum_{j=1}^{n} a_{i j}+\frac{n}{2}-1}{n(n-1)}, i=1,2, \ldots, n .
$$

Step 3: Determine the maximum eigenvalue $\lambda_{\max }$ and corresponding weight vector $W$.

First, we can determine the eigenvector and maximum eigenvalues for the judgment matrix $A$. Secondly, we suppose that $A$ is a consistency judgment matrix, then the corresponding weight vector can be obtained by the method of normalization. When determine the maximum eigenvalue, we take the arithmetic mean value

$$
\lambda_{\max }=\frac{1}{n} \sum_{i=1}^{n} \frac{(A W)_{i}}{w_{i}},
$$

where $(A W)_{i}=\sum_{j=1}^{n} a_{i j} w_{j}$.

Step 4: Rank the order for all alternatives.

When all attribute values are known, then we can rank the order according to the information of attribute values. When the precise values of attributes are difficult to determine, then we can do the two-two comparison for all attributes, and determine the weights for all alternatives. Then we can compute the values of comprehensive weight, and thus rank the order for all alternatives.

\section{Conclusions}

Aiming at the problem of green supplier selection under low-carbon economy, this paper construct a evaluation index system for selecting the green suppliers, and then establish a multi-attribute decision model to select green suppliers based on the method of AHP. This model combines the qualitative methods with quantitative methods, and thus increases the objectivity of the judge. The proposed model can help decision makers select the best green suppliers who meet their needs in implementing the concept of low-carbon economy and face the challenges of the environment, thus leading the trend of green economic development.

\section{Acknowledgments}

This work is supported by the Natural Science Foundation of Hubei Province (No.2014CFC1096), and the 2014 Key Project of Hubei Provincial Department of Education (No.D20142903).

\section{References}

[1] G.L. Sun and X.F. Zhao: Logistics Sci-Tech Vol. 6 (2008), p. 37-39.

[2] G.X. Song and P. Zu: Systems Engineering Vol. 19 (2001), p. 84-89.

[3] L.F. Ruan and G.L. Chen: Statistics and Decision Vol. 21 (2011), p. 62-65.

[4] N.M. Wang, L.Y. Sun and Y.L. Wang: Systems Engineering Vol. 19 (2001), p. 37-41.

[5] B. Liu and Q.H. Zhu: Management review Vol. 17 (2005), p. 32-37.

[6] D.F. Li: Applied Soft Computing Vol. 7 (2007), p. 807-817.

[7] Z.S. Xu: International Journal of General Systems Vol. 36 (2007), p. 179-203.

[8] Z.S. Xu and R.R. Yager: International Journal of General Systems Vol. 35 (2006), p. 417-433.

[9] D.F. Li: Journal of Computer and System Sciences Vol. 70 (2005), p. 73-85.

[10] M.C. Yu, M. Goh and H.C. Lin: European Journal of Operation Reseach Vol. 219 (2012), p. 305-311. 